\title{
O PAPEL DA SOLIDARIEDADE DESEMPENHADO POR FAMILIARES VISITANTES E ACOMPANHANTES DE ADULTOS E IDOSOS HOSPITALIZADOS ${ }^{1}$ \\ THE ROLE OF SOLIDARITY PERFORMED BY FAMILY VISITORS AND COMPANIONS OF HOSPITALIZED ADULTS AND ELDERLY EL PAPEL SOLIDARIO DESEMPEÑADO POR FAMILIARES VISITANTES Y ACOMPAÑANTES DE ADULTOS Y ANCIANOS HOSPITALIZADOS
}

\author{
Lucía Silva², Silvia Cristina Mangini Bocchi ${ }^{3}$, Regina Szylit Bousso ${ }^{4}$
}

\begin{abstract}
${ }^{1}$ Este trabalho é parte de estudo financiado pela Fundação de Amparo à Pesquisa do Estado de São Paulo.
${ }^{2}$ Doutoranda em Enfermagem pela Escola de Enfermagem da Universidade de São Paulo (EEUSP). Professora do Curso de Graduação em Enfermagem do Centro Universitário Nove de Julho. São Paulo, Brasil.

${ }^{3}$ Doutora em Enfermagem. Professora do Departamento de Enfermagem da Faculdade de Medicina de Botucatu da Universidade Estadual Paulista. São Paulo, Brasil.

${ }^{4}$ Doutora em Enfermagem._Professora Livre-docente do Departamento de Enfermagem Materno-Infantil e Psiquiátrica da EEUSP. São Paulo, Brasil.
\end{abstract}

P A L A V R A S - C H A V E : RESUMO: Este estudo objetivou compreender o papel da solidariedade desempenhado por familiares Adulto. Idoso. Família. Enfermagem. visitantes e acompanhantes de adultos e idosos internados. Utilizou-se como referencial teórico a teoria de enfermagem como cuidado solidário e como referencial metodológico a Grounded Theory. Foram entrevistados nove familiares de adultos e idosos hospitalizados no período de abril a setembro de 2002. Dos resultados identificou-se o fenômeno: assumindo o papel de familiar visitante ou de familiar acompanhante, que congrega os temas: querendo desempenhar um papel solidário e compreendendo o estar junto como uma interdependência emocional. Acredita-se que quando a enfermeira reconhece a singularidade da relação de solidariedade e de interdependência familiar, também exerce seu trabalho pautado na solidariedade, visto que colabora para o restabelecimento do doente, alivia seu sofrimento e de seus familiares e, portanto, promove a saúde do grupo familiar.

KEYWORDS: Adult. Aged. Family. Nursing.

\begin{abstract}
This study aimed to better understand the role of solidarity performed by family visitors and companions of hospitalized adults and elderly. The study used the nursing as caring theory as a theoretical reference and the Grounded Theory as a methodological reference. Nine family members of hospitalized adults and elderly were interviewed between April and September of 2002. The phenomenon: assuming the family visitor's or companion's role was identified from the results of the study, which congregates the themes: wanting to perform solidarity, and understanding being together as an emotional interdependence. We believe that when nurses recognize the singularity of the solidarity relationship and of family interdependence, they also exercises their work outlined in solidarity, because they collaborate for the re-establishment of the patient, relieve the patients' and their family's suffering and therefore, promote the health of the family group.
\end{abstract}

PALABRAS CLAVE: Adulto. Anciano. Familia. Enfermería.

\begin{abstract}
RESUMEN: El objetivo de este estudio fue comprender el papel solidario desempeñado por los familiares visitantes y acompañantes de adultos y ancianos hospitalizados. Como referencial teórico se empleó la teoría de enfermería como cuidado solidario, y como referencial metodológico, la Grounded Theory. Para el estudio fueron entrevistados nueve familiares de adultos y ancianos hospitalizados, en el período de abril a septiembre de 2002. De los resultados obtenidos se identificó el fenómeno: asumiendo el papel de familiar visitante o familiar acompañante, formado por los siguientes temas: deseando realizar un papel solidario y entendiendo el permanecer junto como una interdependencia emocional. Se cree que cuando la enfermera reconoce la singularidad de la relación de solidaridad y de la interdependencia de la familia, ella también ejerce su trabajo centrado en la solidaridad, porque colabora para el restablecimiento del paciente, ayudando así a disminuir el sufrimiento del enfermo y de sus familias $y$, por lo tanto, promueve la salud del grupo familiar.
\end{abstract}

Lucía Silva

Endereço: R. João de Oliveira, 1071

18.610-010 - Altos do Paraíso, Botucatu, SP, Brasil.

E-mail: luciasilva@usp.br
Artigo original: Pesquisa Recebido em: 15 de outubro de 2007 Aprovação final: 16 de maio de 2008 


\section{INTRODUÇÃO}

Na prática de cuidado a doentes hospitalizados, nota-se, comumente, que os mesmos são desacompanhados de seus familiares, mas recebem suas visitas em horários previamente determinados pela instituição. Para alguns visitantes, no entanto, é concedida a oportunidade de se tornarem familiares acompanhantes.*

Percebe-se que, em várias situações, a própria estrutura física hospitalar não favorece a permanência do familiar na unidade de internação e que a equipe de saúde nem sempre se mostra acolhedora à família, que vivencia, muitas vezes, um processo de intenso sofrimento.

Quando o indivíduo adoece, sendo necessária a sua internação, ele perde parte do contato com sua família, o que pode fazer com que se desestruture física e emocionalmente. ${ }^{1}$

Isso ocorre porque, ao visualizar a família como um sistema, onde todos os seus membros são interligados, uma situação de mudança, como a hospitalização de um indivíduo doente, é capaz de afetar todos os seus membros, mesmo que em graus variados. ${ }^{2}$

Entretanto, o que se nota nas instituições hospitalares é que ainda prevalece o valor quantitativo do trabalho da equipe profissional, no qual são desconsideradas expressões e necessidades humanas básicas, como a atenção, o carinho, o relacionamento interpessoal e a solidariedade. ${ }^{1}$

Com o interesse de conhecer a experiência do familiar interagindo com o contexto que lhe é oferecido durante o processo de hospitalização de um ente, realizou-se um estudo anterior que buscou compreender a experiência interacional de familiares visitantes e acompanhantes, durante a internação, de adultos e idosos. Evidenciou-se que, para lidar com este papel, o familiar assume a responsabilidade do cuidado perante seu ente hospitalizado com resignação e amparado no sentimento de solidariedade. ${ }^{3}$

Esta tarefa e a arte de cuidar de um familiar doente, seja ele adulto ou idoso, são exercidas tanto no âmbito hospitalar como no domicílio e é importante que o enfermeiro ajude os membros da família a se alinharem no sentido de oferecerem suporte um ao outro na experiência que envolve a doença. ${ }^{4}$
No entanto, é clara a dificuldade que os profissionais de saúde apresentam em incluir a famúlia em seu plano de cuidados, reconhecendo-a como parte integrante da vida de um adulto ou idoso perante o difícil processo de hospitalização e, em resposta a essa dificuldade, o enfermeiro, por vezes, pode assumir um papel de controle, deixando de se aproximar tanto do doente como de sua família. ${ }^{5}$

Acredita-se que a partir da compreensão da experiência de hospitalização de um doente, especificamente no que diz respeito à solidariedade compartilhada entre os membros da família, os profissionais terão melhores condições de reconhecê-la como um fator capaz de fortalecer todo o grupo familiar diante de uma situação crítica.

Face ao exposto e com a finalidade de produzir conhecimentos que subsidiem o ensino e a assistência de enfermagem em um cenário humanizado, o objetivo deste trabalho foi compreender o papel da solidariedade desempenhado por familiares visitantes e acompanhantes de adultos e idosos hospitalizados.

\section{PERCURSO METODOLÓGICO}

Trata-se de um estudo de abordagem qualitativa que adotou como referencial teórico a teoria de enfermagem como cuidado solidário e como referencial metodológico a Grounded Theory.

\section{Teoria geral de enfermagem como cuidado solidário}

Esta ampla teoria de enfermagem é influenciada por discussões sobre o cuidado e sobre a solidariedade, sendo que duas perspectivas principais a sustentam: a percepção das pessoas como solidárias e a concepção da enfermagem como disciplina e profissão. ${ }^{6}$

A percepção da pessoa como solidária apresenta como pressupostos principais:

- as pessoas são solidárias em decorrência de sua humanidade;

- as pessoas são solidárias em todos os momentos;

- as pessoas são completas no momento;

- a pessoalidade baseia-se na solidariedade;

- a pessoalidade é favorecida pelos relacionamentos com outros solidários;

* Neste estudo, considerou-se familiar visitante aquele que permanecia junto ao doente durante o horário determinado previamente para as visitas, conforme as normas para cada unidade de internação da Instituição pesquisada e considerou-se familiar acompanhante aquele que permanecia junto ao seu ente hospitalizado em período integral. 
- a enfermagem é tanto uma disciplina como uma profissão;

- as pessoas são percebidas como completas e em constante crescimento em sua totalidade, solidárias e revelam possibilidades de cuidados em todos os momentos. ${ }^{5}$

Já a concepção da enfermagem como disciplina considera-a como uma unidade de ciência, arte e ética e como profissão, tem o compromisso social de comprometer-se em adquirir e usar o conhecimento e a habilidade para o bem, em resposta às necessidades das pessoas. ${ }^{6}$

Na perspectiva desta teoria, ser solidário significa exercer a responsabilidade nas relações ${ }^{6}$ responsabilidade por si e pelo outro. Desse modo, oferecer o cuidado solidário implica na reflexão do cuidador sobre como agir com o outro e esta ação deve ser guiada pela necessidade de considerá-lo como um todo.

Para tanto, esta abordagem deve, além de enfocar a totalidade dos seres humanos, enfocar sua valorização, considerá-los vivendo e crescendo em solidariedade e buscar o engajamento com o outro em um nível pessoal. ${ }^{6}$

Ademais, considerar a pessoa como um todo, no contexto do cuidado solidário, é um valor significativo que comunica respeito por tudo o que ela é. ${ }^{6}$

\section{Grounded Theory}

A Grounded Theory é uma estratégia para trabalhar os dados em pesquisa que proporciona modos de conceitualização para descrever e explicar um fenômeno. Seus idealizadores apresentam um método de análise comparativa constante, no qual o pesquisador, ao comparar incidente com incidente nos dados, estabelece categorias conceituais que servem para explicar o dado. A teoria, então, é gerada por um processo de indução, no qual categorias analíticas são identificadas por meio da análise da interpretação dos dados e são elaboradas conforme o trabalho avança. ${ }^{7}$

Esse é um processo descrito como amostragem teórica e o pesquisador decide quais dados coletar em seguida em função da análise que vem realizando. Nesse sentido, a amostragem adotada não é estatística, uma vez que o número de sujeitos ou situações que devem integrar o estudo é determinado pelo momento em que as informações começam a ser repetidas e dados novos ou adicionais não são mais encontrados. ${ }^{7}$

\section{Atores participantes e local da pesquisa}

Foram entrevistados nove familiares que concordaram em participar do estudo e que tinham seus entes internados (cinco idosos e quatro adultos) por um período de tempo superior a sete dias. Destes nove participantes, cinco eram familiares visitantes e quatro eram acompanhantes de adultos ou de idosos internados, em um hospital universitário público de grande porte, em duas unidades clínicas (Clinica Médica I e II) e em duas unidades cirúrgicas (Ortopedia e Gastrocirurgia), no período de abril a setembro de 2002.

De acordo com a caracterização dos nove participantes da pesquisa, oito eram do sexo feminino e um masculino. Tinham entre 26 e 52 anos de idade e um período de sete dias a três meses como familiar visitante ou acompanhante de adulto ou idoso hospitalizado. O grau de parentesco se distribuiu entre uma esposa, um filho, cinco filhas, uma prima e uma sobrinha, sendo: quatro donas-de-casa, uma professora aposentada, uma balconista, uma operadora de máquina, uma auxiliar administrativa e um ajudante de produção.

\section{Estratégias para coleta e análise de dados}

Em cumprimento à Resolução No 196 do Conselho Nacional de Saúde, de 10 de outubro de 1996, que aprovou as diretrizes e normas regulamentadoras de pesquisas envolvendo seres humanos, ${ }^{8}$ a coleta de dados iniciou-se somente após emissão do parecer favorável do Comitê de Ética em Pesquisa da Faculdade de Medicina de Botucatu da Universidade Estadual Paulista ofício $N^{0} 107 / 2002$, por meio de gravações de entrevistas não estruturadas do tipo focalizada, tendo como questão de partida - Como tem sido a sua experiência como familiar visitante ou acompanhante de pessoa hospitalizada?

Tais entrevistas foram realizadas de acordo com a disponibilidade pessoal de horário de cada familiar, na própria Instituição da pesquisa, em sala reservada especialmente para esta finalidade ou em varandas dispostas em algumas unidades de internação, a depender de sua preferência.

Ressalta-se que primeiramente os procedimentos e os objetivos do estudo foram detalhadamente explicados aos participantes e, após entendimento e concordância dos mesmos, lhes era solicitado que assinassem o Termo de Consentimento Livre e Esclarecido. 
Buscando resguardar a identidade dos familiares entrevistados, no decorrer do texto, cada participante foi identificado por meio de números seqüenciais atribuídos conforme a ordem das entrevistas.

Após a gravação das entrevistas, as mesmas eram transcritas na íntegra e analisadas de acordo com o método da Grounded Theory, conforme as estratégias básicas apresentadas para a formação de categorias, seguindo-se os passos: descobrindo categorias, ligando categorias, desenvolvendo os memorandos e identificando o processo. ${ }^{9}$

O método preconiza que categorias são abstrações do fenômeno observado nos dados e formam a principal unidade de análise da Grounded Theory. A teoria se desenvolve por meio do trabalho realizado com as categorias, que permite identificar a categoria central, sendo geralmente um processo, como conseqüência da análise. ${ }^{9}$

\section{APRESENTAÇÃO E DISCUSSÃO DOS RESULTADOS}

Com o processo de análise foi possível identificar a categoria central "Movendo-se perante a sinalização do enfermeiro entre os papéis de familiar visitante e familiar acompanhante: compartilhando uma experiência de poucos prazeres em solidariedade ao adulto e ao idoso hospitalizados." Esta categoria foi descoberta a partir do momento em que dois fenômenos foram inter-relacionados: "vivendo a expectativa pela internação no hospital universitário" e "assumindo o papel de familiar visitante ou de familiar acompanhante". Essa estratégia permitiu identificar as categorias e subcategorias chaves, nas quais se evidenciou o movimento da família durante a hospitalização de seu ente. ${ }^{3}$

Nesse recorte serão apresentados dois temas identificados a partir do segundo fenômeno citado: "querendo desempenhar um papel solidário" e "compreendendo o estar junto como uma interdependência emocional".

\section{Querendo desempenhar um papel solidário}

Este primeiro tema se revela como um sentimento despertado na família pela relação de responsabilidade entre pessoas unidas por laços de afetividade, determinando o apoio a um membro que esteja vivenciando o processo de hospitalização como uma obrigação moral. Assim, a família deseja permanecer com o doente para exercer este papel solidário, que se mostrou composto por duas categorias: sendo o apoio ao doente uma obrigação moral da família e desejando estar com o doente.

Diante disso, pode-se afirmar que a solidariedade pode ser entendida como uma norma presente nas relações próximas, tais como as encontradas entre membros de uma família.

Nesse sentido, conteúdos recebidos e transmitidos pela geração familiar mais velha podem ser agrupados por legados que constituem as bases para a vida familiar, dentre eles o de solidariedade, que se refere ao amor, à amizade, ao senso de justiça, à colaboração e ao respeito. ${ }^{10}$

A relação de responsabilidade que os familiares deste estudo reconheceram ter para com seus entes hospitalizados está sustentada pela solidariedade, já que ser solidário implica que o indivíduo seja responsável por si mesmo e pelo outro. ${ }^{6}$

\section{Sendo o apoio ao doente uma obrigação moral da família}

É a concepção que mobiliza os esforços da família no sentido de desempenhar o papel de suporte junto a um de seus integrantes que esteja vivenciando a hospitalização. Está amparada na capacidade de a mesma perceber o doente como alguém que precisa do apoio familiar naquele momento, conforme referido por um filho, no momento em que sua mãe se encontra hospitalizada. Para ele, [...] agora quem está precisando de força é ela (Ator 6).

Associada a esta percepção, a família também precisa ser capaz de se compreender como uma unidade que tem obrigação de oferecer suporte a um ente em situação de vulnerabilidade, conforme relato: [...] Olha! Senhora idosa! Sofrendo! [...] A gente vê que tem que fazer alguma coisa pela vida. Para o nosso próximo (Ator 3).

O entendimento de que este suporte familiar se constitui uma obrigação moral para com o doente, a perspectiva que adota a pessoa como solidária, ${ }^{6}$ considera que a solidariedade, vivida em todos os momentos, dirige os deveres de cada um. Assim, a obrigação moral que os familiares deste estudo acreditam ter em relação ao oferecimento de suporte a um de seus membros que vivencia a hospitalização, é permeada pela solidariedade.

Segundo a literatura, o apoio empreendido pelas famílias aos seus entes, fundamenta-se em princípios morais e religiosos que os mobilizam em solidariedade ao outro.

Em estudo com ex cuidadores familiares, vivenciando a condição de voluntários junto à ins- 
tituição que cuida de idosos dependentes, os atores definem consciência solidária como: "o movimento da mente de um indivíduo, perante a necessidade de apoio do seu semelhante, percebido como alguém em situação de desvantagem, demandando a mobilização de suas energias em benefício do cuidado do outro, como uma manifestação de amor ao próximo e uma obrigação moral voluntária". 11:17

Em pesquisa que objetivou traçar o perfil de famílias cuidadoras de idosos em um município do sul do Brasil, constatou-se que os familiares se responsabilizam pelo cuidado a um indivíduo doente ou fragilizado por perceberem a tarefa como uma missão necessária e dignificante, como parte de princípios morais e religiosos. ${ }^{12}$

\section{Desejando estar com o doente}

É uma manifestação essencial para que a família possa expressar o seu apoio em solidariedade a um integrante doente e, para isso, precisa da oportunidade de estar o maior tempo possível ao lado do mesmo. A família expressa as suas facilidades e até mesmo sinaliza as estratégias a serem utilizadas para permanecerem junto ao doente. Esta manifestação pode ser percebida mediante uma seqüência de ações empreendidas no sentindo de vivenciar a experiência de estar com o familiar, num momento difícil. Este fato pode ser verificado, no encadeamento das ações retratado por quatro subcategorias: querendo visitar o doente, tendo condições de visitar, familiar visitando o doente e querendo ficar com o doente.Esse movimento da família pode ser exemplificado pelo relato:

[...] meus irmãos estão vindo todos os dias. Minha irmã trabalha fora e o outro fica o dia inteiro no serviço, só vem à tarde. O meu pai entra para trabalhar às três horas da tarde, então na hora do almoço ele vem aqui. Ele vem e depois vai trabalhar. Depois meus irmãos é que vêm (Ator 6).

A seguir, também se pode observar a interação com o ator nove manifestando a sua satisfação em relação ao estar com o seu familiar hospitalizado, ao dizer que [...] agora está uma maravilha (na enfermaria), eu não a largo para nada, fico aqui (Ator 9).

Quando lhes é concedida a oportunidade de estarem junto ao doente, os familiares podem exercitar cada vez mais o seu papel solidário. $\mathrm{O}$ enfermeiro tem um papel importante na promoção da solidariedade familiar, já que, permitindo que as pessoas a exerçam, também oportunizam seu próprio conhecimento e dos outros como seres solidários, favorecendo a experiência. ${ }^{6}$
Percebe-se que, a exemplo de outros estudos, na perspectiva dos familiares, a hospitalização é uma experiência em que eles lidam com a difícil realidade, movidos pela crença de que o indivíduo doente irá melhorar e por isso se mostram dispostos a estarem com o outro, seja qual for a situação. ${ }^{13}$

\section{Compreendendo o estar junto como uma interdependência emocional}

O segundo tema é permeado pela crença que, quando a instituição concede a oportunidade para o familiar de estar com o doente durante a hospitalização, ele acredita que a mesma está favorecendo o desenvolvimento de um processo interacional, onde a reciprocidade de sentimentos promove um relacionamento benéfico tanto para o doente como para a família, capaz de aliviar o sofrimento de ambos. Ele reúne as categorias: família auxiliando o doente a lidar com a doença e família se beneficiando emocionalmente ao estar com o doente.

À luz do referencial teórico da enfermagem como cuidado solidário, a pessoalidade deve ser reconhecida como um processo de viver baseado na solidariedade e este processo é continuamente favorecido por meio das relações solidárias entre as pessoas que cuidam e as que são cuidadas. ${ }^{6}$

Alguns autores acrescentam que a importância do acompanhante junto ao familiar doente decorre do fato de o mesmo auxiliar o ente, oferecer-lhe apoio emocional, sentir-se bem junto ao doente, acompanhar sua evolução, manter o vínculo familiar e preservar sua identidade. ${ }^{14}$

Outros estudos corroboram com a experiência apresentada por esta pesquisa quando descrevem as vivências da hospitalização de um ente como uma prova difícil e permeada por sofrimento, porém, benéfica tanto para o familiar como para o doente quando há o movimento para a solidariedade e para o apoio a um ente, por vezes, em detrimento de sua própria vida e cuidado individual. ${ }^{1,14-15}$

\section{Família auxiliando o doente a lidar com a doença}

É a ação da família mediante a sua percepção de que contribuirá com o tratamento do adulto ou do idoso hospitalizado, quando lhe é concedida a oportunidade de despertar reações emocionais positivas no doente. Este processo é expresso pelo ator dois ao referir que [...] a primeira coisa que aconteceu é que ela começou a chorar, chorou muito e dai eu conversei muito com ela e ela foi ficando mais 
calma [...] daí, o que eu pude notar é que a visita para a pessoa é excelente (Ator 2).

A permanência dos familiares junto ao doente pode estar baseada na crença de que o adulto ou o idoso, quando enfermo, tende a desenvolver maior dependência e apego à família, necessitando, portanto, ter junto a si alguém em que confie e com quem se sinta à vontade para exprimir suas necessidades nos planos social e afetivo. ${ }^{14}$

Isso porque a família, mesmo com suas divergências e peculiaridades, é a unidade capaz de promover o bem estar do paciente, ${ }^{1}$ já que, culturalmente, a expectativa em relação aos membros da família é que eles promovam suporte instrumental e social ao seu familiar doente ou fragilizado, fato este constatado, inclusive, em outros estudos que envolvem o idoso dependente de cuidados em decorrência da diminuição de sua capacidade funcional. ${ }^{4}$

\section{Família se beneficiando emocionalmente com a visita}

Nesta pesquisa, o familiar do adulto ou do idoso hospitalizado, quando consegue perceber que lhe é dada a oportunidade de estar junto ao mesmo, acompanhando a evolução e as respostas do paciente ao tratamento, acaba sentindo-se mais tranqüilo. Estas evidências podem ser retratadas por sentimentos prazerosos em ficar com o doente: [...] aqui [na enfermaria] pode entrar e ficar bastante tempo,é muito bacana [...] eu fiquei muito contente da minha mãe vir para cá, acho bom porque a gente pode estar mais em contato e dar mais atenção para ela [...] (Ator 7).

Conseqüentemente, a família tende a se sentir segura junto ao doente: [...] quando eu fico aqui eu fico menos tenso do que quando eu estou em casa; quando estou em casa fico pensando: como será que ela está? [...] fico preocupado. Os filhos dela ficam ligando também, aí fica a família toda sossegada (Ator 1).

Pôde-se constatar, portanto, que ao exercerem seu papel solidário em relação a um ente hospitalizado, os familiares reconheciam que também eram beneficiados durante a experiência, já que a oportunidade de serem solidários proporcionavalhes bem-estar, corroborando com um dos pressupostos do referencial teórico adotado.

Assim, a família considera benéfico permanecer ao lado do doente, não apenas pelo fato de poder oferecer-lhe apoio emocional e instrumental, mas também por razões ligadas às suas próprias necessidades, como se sentir bem estando junto ao doente. ${ }^{14}$
Por fim, a análise dos resultados encontrados sustentada pelo referencial teórico escolhido nos permite clarificar as possibilidades que a enfermeira tem em seu dia-a-dia para exercer cada vez mais seu papel solidário.

Este exercício é possível a medida que esta profissional tiver mais oportunidades de refletir e de reconhecer a solidariedade como um fator importante para o crescimento e para o fortalecimento da família, tornando mais fácil permitir a si mesma e aos familiares o espaço e o tempo para a promoção da solidariedade.

\section{CONSIDERAÇÕES FINAIS}

Ao considerar a família como uma unidade de cuidado, a enfermeira deve reconhecer que a presença de um adulto ou de um idoso hospitalizado afeta também os componentes do grupo ${ }^{2}$, daî a importância e a necessidade de aprofundar e ampliar os estudos que privilegiam o processo saúdedoença considerando a perspectiva da família.

Apesar de a experiência de familiares durante a hospitalização mostrar que eles assumem um papel de poucos prazeres, tomam para si esta responsabilidade com resignação, em solidariedade ao seu ente adulto ou idoso hospitalizado.

Nesse sentido, quando a enfermeira reconhece a singularidade da relação estabelecida na família refletida por meio da solidariedade e da interdependência, ela também exerce seu trabalho pautado na solidariedade, visto que colabora para o restabelecimento do doente, alivia o seu sofrimento e o de seus familiares e, portanto, promove a saúde do grupo familiar.

Assim, as situações cotidianas de enfermagem no cuidado ao indivíduo hospitalizado e aos seus familiares, sejam eles visitantes ou acompanhantes, são uma rica oportunidade para o compartilhamento da solidariedade entre o doente, a família e o enfermeiro, já que a própria família carece de proteção e solidariedade para executá-las, ou seja, seu potencial protetor pode ser fortalecido se ela própria sente-se acolhida pela equipe de cuidados profissionais.

Acredita-se que os conhecimentos advindos desta pesquisa poderão nortear estratégias para a humanização hospitalar, ao considerar a família como um sistema integrante do processo de cuidar e diante disso, sugere-se que a Instituição alivie a austeridade normativa que impede os familiares visitantes, principalmente de adultos e idosos, de se tornarem acompanhantes, a fim de tornar o am- 
biente hospitalar mais acolhedor a todos os atores que lá desempenham seus papéis sociais.

\section{REFERÊNCIAS}

1 Pinho LB, Kantorski LP. Refletindo sobre o contexto psicossocial de famílias de pacientes internados na unidade de emergência. Cienc. Enferm. 2004 Jun; 10 (1): 67-77.

2 Wright LM, Leahey M. Enfermeiras e famílias: um guia para avaliação e intervenção na família. 3a ed. São Paulo (SP): Roca; 2002.

3 Silva L, Bocchi SCM. A sinalização do enfermeiro entre os papéis de familiar visitante e acompanhante de adulto e idoso. Rev Latino-am. Enfermagem [on line]. 2005 Mar-Abr; 13 (2): 180-7 [acesso em 2008 Maio 1]. Disponível em: http://www.scielo. br / scielo.php? script $=$ sci_arttext\&pid $=$ S0104$11692005000200008 \& \operatorname{lng}=\mathrm{pt \& nrm}=\mathrm{iso} \& \mathrm{tlng}=\mathrm{pt}$

4 Silva L. O processo de conviver com um idoso dependente sob a perspectiva do grupo familiar [dissertação]. Ribeirão Preto (SP): USP/PEN; 2007.

5 Bocchi SCM, Silva L, Juliani CMCM, Spiri W. Family visitors and companions of hospitalized elderly and adults: analysis of the experience from the perspective of the nursing working process. Rev Latino-am. Enfermagem [on line]. 2007 Mar-Abr; 15 (2): 304-10 [acesso em 2008 Maio 1]. Disponível em: http:// www.scielo.br/pdf/rlae/v15n2/v15n2a17.pdf

6 Boykin A, Schoenhofer S. Nursing as caring: a model for transforming practice. New York (NY/USA): National League for Nursing Press; 2001.

7 Glaser BG, Strauss AL. The discovery of grounded theory. New York (NY/USA): Aldine; 1967.

8 Ministério da Saúde (BR), Conselho Nacional de Saúde, Comissão Nacional de Ética em Pesquisa. Resolução $N^{\circ}$ 196, de 10 de outubro de 1996: diretrizes e normas regulamentadoras de pesquisas envolvendo seres humanos. Brasília: MS;1996.

9 Chenitz WC, Swanson JM. From practice to grounded theory. Reading (Berkshire/UK): Addison-Wesley; 1986.

10 Vitale MAF. Socialização e família: uma análise intergeracional. In: Carvalho $\mathrm{MCB}$, organizador. A família contemporânea em debate. São Paulo (SP): Ed. Cortez; 2002. p.89-96.

11 Bocchi SCM, Andrade, SCM. Entre o fortalecimento ao declínio do vínculo voluntário-idoso dependente em um centro-dia, mediado por (des)motivação. Faculdade de Medicina de Botucatu/UNESP: Botucatu, 2008.

12 Gonçalves LHT, Alvarez AM, Sena ELS, Santana WSS, Vicente FR. Perfil da família cuidadora de idoso doente/fragilizado do contexto sociocultural de Florianópolis, SC. Texto Contexto Enferm. [on line]. 2006 Out-Dez; 15 (4): 570-7 [acesso em 2008 Maio 1]. Disponível em: http://www.scielo.br/pdf/tce/ v15n4/v15n4a04.pdf

13 Bocchi SCM. Movendo-se entre a liberdade e a reclusão: vivendo uma experiência de poucos prazeres ao vir-a-ser um familiar cuidador de uma pessoa com AVC [tese]. São Paulo (SP): USP/Programa Interunidades de Doutorado em Enfermagem; 2001.

14 Franco MC, Jorge MSB. Sofrimento do familiar frente à hospitalização. In: Elsen I, Marcon SS, Santos MR, organizadores. $\mathrm{O}$ viver em família e sua interface com a saúde e a doença. Maringá (PR): EDUEM; 2002. p.182-98.

15 Armond LC, Boemer MR. Convivendo com a hospitalização do filho adolescente. Ver Latino-am. Enfermagem [on line]. 2004 Nov-Dez; 12 (6): 924-32 [acesso em 2008 Maio 1]. Disponível em: http:// www.scielo.br/pdf/rlae/v12n6/v12n6a12.pdf 